07

\title{
Фракто- и фотолюминесценция кварца при разрушении
}

\author{
(C) В.И. Веттегрень, А.Г. Кадомцев, И.П. Щербаков, Р.И. Мамалимов \\ Физико-технический институт им. А.Ф. Иофрфе РАН, \\ Санкт-Петербург, Россия \\ E-mail: Victor.Vettegren@mail.ioffe.ru
}

Поступила в Редакцию 25 марта 2021 г.

В окончательной редакции 30 марта 2021 г.

Принята к публикации 30 марта 2021 г.

\begin{abstract}
Получены спектры фрактолюминесценции во время разрушения поверхности кварца методами „микрорезания“' кристаллами алмаза и удара по его поверхности стальным бойком, а также спектры фотолюминесценции после разрушения. В спектрах фрактолюминесценции наблюдается полоса $2.12 \mathrm{eV}$, которая приписана возбужденным радикалам $\equiv \mathrm{Si}-\mathrm{O}^{\bullet}$, образующимся при разрывах связей $\mathrm{Si}-\mathrm{O}-\mathrm{Si}$. Фрактолюминесценция представляла собой набор сигналов длительностью $\sim 50 \mathrm{~ns}$, интенсивность которых изменялась на порядок. Интервал времени между сигналами изменялся от $\sim 0.1$ до нескольких $\mu \mathrm{s}$. Сигналы, возникающие при ударе, содержали пять, а при микрорезании - четыре наложенных друг на друга максимума. Предполагается, что сигналы фрактолюминесценции возникают при прорыве барьеров, препятствующих движению дислокаций по плоскостям скольжения, и образовании самых мелких - „первичных“ трещин. Определены константы скорости роста таких трещин и затухания фрактолюминесценции после их остановки. Средние размеры площади берегов первичных трещин после удара $\sim 5 \mathrm{~nm}^{2}$, а после микрорезания $\sim 25 \mathrm{~nm}^{2}$. В спектрах фотолюминесценции после разрушения наблюдается полоса $2.4 \mathrm{eV}$, которая приписана радикалам $\equiv \mathrm{Si}-\mathrm{O}$ на поверхности трещин после их остановки.
\end{abstract}

Ключевые слова: фрактолюминесценция, фотолюминесценция, кварц, нанотрещины, разрушение.

DOI: 10.21883/FTT.2021.08.51165.060

\section{1. Введение}

Трещины в металлах, полимерах и неорганических кристаллах к настоящему времени изучены методами рассеяния рентгеновских лучей, электронной микроскопии и др. Установлено, что в этих телах они имеют размеры от $\sim 0.1$ до нескольких $\mu \mathrm{m}$. Исследования механизма разрушения кристаллов показали, что процесс их разрушения под влиянием механических напряжений начинается с накопления и объединения трещин [1-4]. В металлах самые мелкие из них — „зародышевые“, образуются при прорыве дислокациями барьеров, препятствующих их движению по плоскостям скольжения [5-8].

Кварц имеет трехмерный каркас из тетраэдров $\mathrm{SiO}_{4}$. Прорыв барьеров в этом кристалле происходит путем разрыва связей $-\mathrm{Si}-\mathrm{O}-\mathrm{Si}-$. Образующиеся при разрывах свободные радикалы вначале находятся в возбужденном электронном состоянии $\equiv \mathrm{Si}-\mathrm{O}^{\bullet}$. При переходе в основное состояние энергия возбуждения выделяется в виде излучения в видимой области спектра - фрактолюминесценции (FL) $[9,10]$. Анализируя вид и динамику накопления сигналов FL с временным разрешением $2 \mathrm{~ns}$, можно проследить за прорывами барьеров и образованием зародышевых трещин в кварце.

\section{2. Объект и методы исследования}

Образцы из монокристалла кварца разрушали методами „микрорезания“ или удара по бойку, установленному на поверхности. Схемы установок приведены в [10].
Чтобы получить сигналы FL при микрорезании были приготовлены образцы в виде параллелепипедов с размерами $2 \times 2 \times 4 \mathrm{~cm}$, ось $c$ которых параллельна длинному ребру. Один из торцов параллелепипеда прижимали к стальному диску, на поверхности которого были приклеены микрокристаллы алмаза с линейными размерами $\sim 7 \mu \mathrm{m}$. Пластина была посажена на ось электромотора. После его включения диск начинал вращаться со скоростью $5 \mathrm{~m} / \mathrm{s}$, микрокристаллы ,разрезали“ поверхность кристалла кварца, что приводило к FL. Ее спектр регистрировали оптоволоконным спектрометром AvaSpec-ULSi2048L-USB2 OE.

При трении диск и параллелепипед нагреваются. Чтобы оценить температуру в зоне трения, вдоль длинного ребра параллелепипедов был пропилен паз глубиной $\sim 1 \mathrm{~mm}$ и в него вставлена термопара. Перемещая термопару внутри паза, измеряли температуру стержня $T(x)$ на различных расстояниях $x$ от зоны трения. В стационарных условиях температура $T(x)$, связана с температурой $T(0)$ в зоне трения выражением (уравнение Пуассона) [11]:

$$
T(x)=T(0)-\frac{F(x)}{\lambda} x,
$$

где $F(x)$ - плотность тепловых источников, а $\lambda-$ коэффициент теплопроводности. В соответствии с этим уравнением, зависимость температуры от расстояния оказалась близкой к линейной (рис. 1). Экстраполируя ее к $x=0$, нашли температуру в зоне микрорезания $\sim 462 \mathrm{~K}$. 


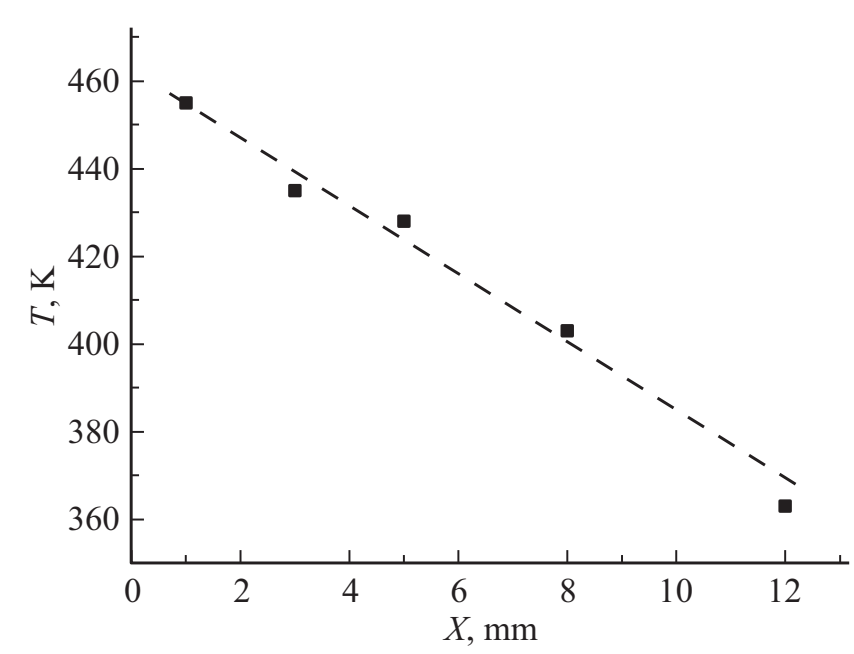

Рис. 1. Зависимость температуры образца от расстояния до зоны микрорезания.

Также FL возбуждали ударом груза массой $50 \mathrm{~g}$, падающего с высоты $5 \mathrm{~cm}$ на стальной боек, установленный на поверхности образца перпендикулярно или параллельно оси с кристалла кварца. Удар вызывал внедрение бойка в поверхностный слой кристалла кварца и FL.

Для исследования временных зависимостей сигналов FL излучение фокусировали на поверхность фотоэлектронного умножителя РЕМ-136. Электрическое напряжение с его выхода подавали на вход аналогово-цифрового преобразователя ADC-3106 фирмы „ACTACOM“. Напряжение на выходе ADC через каждые 2 ns записывалось в память компьютера.

Изменение строения поверхностного слоя кварца после трения или удара исследовали при помощи фотолюминесценции (PL). PL возбуждали ультрафиолетовым светодиодом UVTOP280TO39HS (энергия излучения $4.35 \mathrm{eV}$ ) и регистрировали спектрометром AvaSpec-ULSi2048L-USB2 OE.

\section{3. Спектр FL кварца}

Спектр FL, возникающий при разрушении кварца, показан на рис. 2. В нем наблюдаются две полосы: интенсивная - $2.12 \mathrm{eV}$ и слабая $-3.3 \mathrm{eV}$.

Спектры катодолюминесценции (CL) кварца под воздействием пучков электронов были исследованы в [11-13]. Полосы в этих спектрах ассоциируют с дефектами, образующимися при разрывах одной из связей $\mathrm{Si}-\mathrm{O}$ : самозахваченными экситонами, центрами $E_{1}^{\prime}$ и $E_{2}^{\prime}$ и др. В таблице приведены значения энергий максимумов полос, наблюдаемых в спектрах FL, т.е. во время разрушения, и в спектрах PL и CL - после него. Видно, что они различны и, следовательно, соответствуют разным дефектам. Исключение составляет слабая полоса $3.3 \mathrm{eV}$, которая наблюдалась во всех трех видах спектров.
Энергия максимумов в спектрах FL, PL и CL

\begin{tabular}{c|c|c}
\hline \multicolumn{3}{|c}{ Энергия максимумов, eV } \\
\hline FL & PL & CL $[11-13]$ \\
\hline & & 1.91 \\
\hline & & 1.95 \\
\hline 2.12 & 2.1 & \\
\hline & & 2.28 \\
\hline & 2.41 & \\
\hline & & 2.46 \\
\hline & & 2.68 \\
\hline & 2.88 & 2.93 \\
\hline & & 3.12 \\
\hline & 3.3 & 3.3
\end{tabular}

Чтобы выяснить природу дефектов, возникающих при разрушении, исследовали временные зависимости интенсивности FL. Оказалось (рис. 3), что FL состоит из множества сигналов, интенсивность которых изменялась на порядок. Длительность каждого сигнала $\sim 50 \mathrm{~ns}$. Интервал времени между сигналами варьировал от $\sim 0.1$ до нескольких $\mu \mathrm{s}$. Сигналы, возникающие при ударе, содержали пять наложенных друг на друга максимумов, а при трении - четыре (рис. 4).

Какова же природа таких сигналов FL? Предположим, что трещины в кварце образуются так же, как в металлах - при прорыве барьеров, препятствующих движению дислокаций по плоскостям скольжения. Дви-

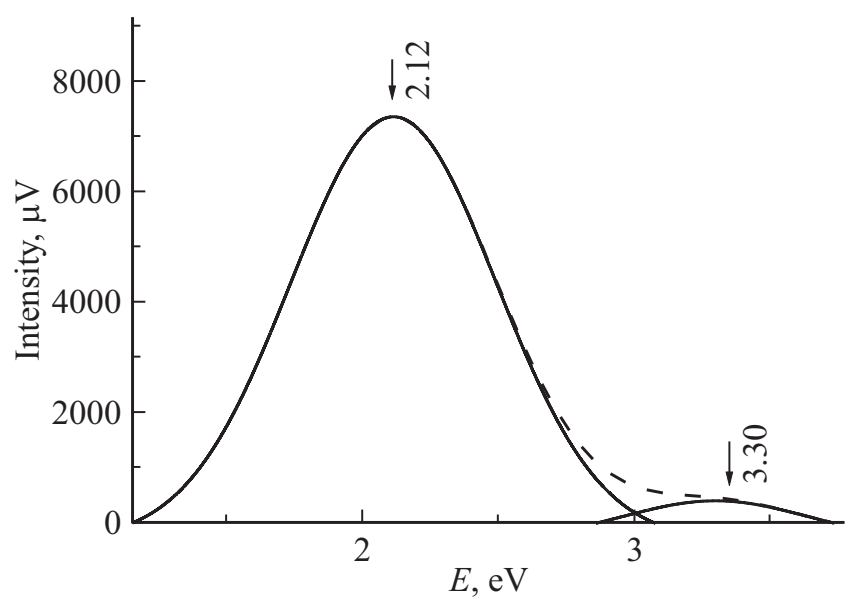

Рис. 2. Спектр FL кварца при микрорезании. Штриховая линия - измеренный спектр, сплошные линии - полосы, при наложении которых он образуется. 


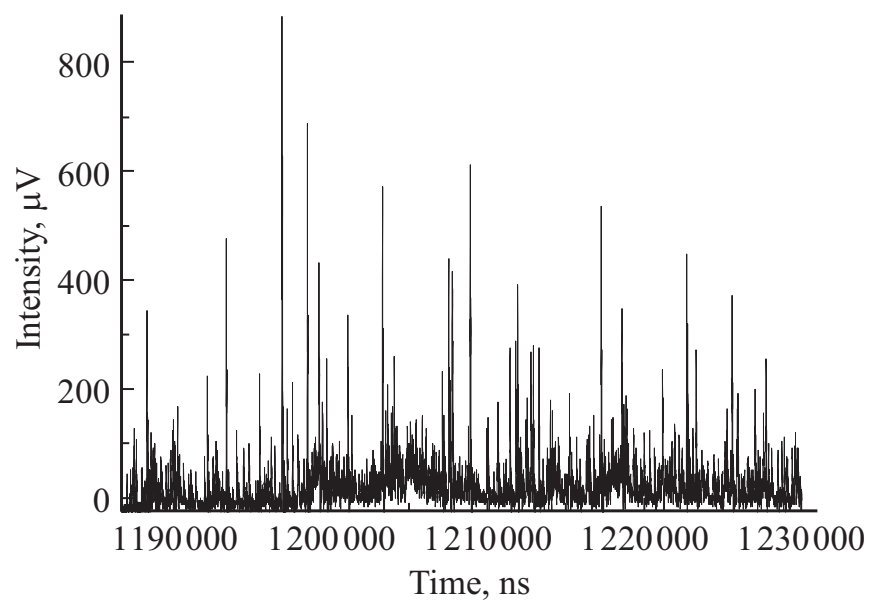

Рис. 3. Фрагмент временно́й зависимости интенсивности FL.

жение дислокаций в кварце требует разрыва сильных связей $\mathrm{Si}-\mathrm{O}-\mathrm{Si}$. Поэтому при комнатной температуре в отсутствие воды, при обычных напряжениях и температурах ниже $700^{\circ} \mathrm{C}$, оно не наблюдается. Однако Trépied и Doukhan обнаружили [14], что при сильных механических напряжениях, достигаемых при индентировании, дислокации перемещаются на расстояние несколько $\mu \mathrm{m}$. Вероятно, при микрорезании кристаллами алмаза тоже достигаются напряжения, при которых дислокации могут начать двигаться по плоскостям скольжения, скапливаться около барьеров и прорывать их. При прорыве образуются самые мелкие - „первичные“ трещины [5-8]. Другие - более крупные трещины образуются при слиянии первичных трещин [1-4].

Появление первичной трещины ведет к образованию максимума во временной зависимости FL [15].
При комнатной температуре сингония кварца тригональная и, следовательно, в этом кристалле максимальное число возможных систем плоскостей скольжения дислокаций - пять: (0001), (1011), (0111), (1012) и (1010) [16,17]. Напряжение, действующее на дислокации, пропорционально произведению $\cos \chi \cos \lambda$, где $\lambda-$ угол между внешней силой и направлением скольжения, а $\chi$ - угол между силой и нормалью к плоскости скольжения [18]. Поэтому дислокации движутся лишь в тех направлениях, для которых произведение $\cos \chi \cos \lambda$ не равно нулю. При ударе на кристалл кварца действует сила направленная как вдоль оси $c$ кристаллов, так и перпендикулярно ей. Поэтому под ее влиянием дислокации движутся по всем указанным выше пяти плоскостям. При микрорезании на кристаллы кварца действуют силы, параллельные оси $c$, и плоскости, параллельные оси $c$, т.е. (0001), неактивны. По этой причине ожидалось, что при ударе число максимумов в сигналах FL будет равно пяти, а при трении - четырем. Действительно, как отмечено выше, сигналы FL при ударе содержали пять максимумов, а при трении четыре (рис. 4).

Этот результат находится в согласии с предположением о том, что сигналы FL возникают при прорыве барьеров, препятствующих скольжению дислокаций, и позволяет приписать полосу $2.12 \mathrm{eV}$ радикалам $\equiv \mathrm{Si}-\mathrm{O}^{\bullet}$, которые возбуждаются при разрушении барьеров, препятствующих движению дислокаций.

Интенсивность каждого максимума в сигналах FL пропорциональна числу возбужденных свободных радикалов $\equiv \mathrm{Si}-\mathrm{O}^{\bullet}$. Сначала, в течение времени $t \leq 0.7 \tau$, где $\tau$ - время остановки трещины (рис. 4), число радикалов $\equiv \mathrm{Si}-\mathrm{O}^{\bullet}$ растет, а затем, при $t>\tau$ (после остановки трещины), уменьшается. В начальные моменты времени уменьшением интенсивности FL можно пре-
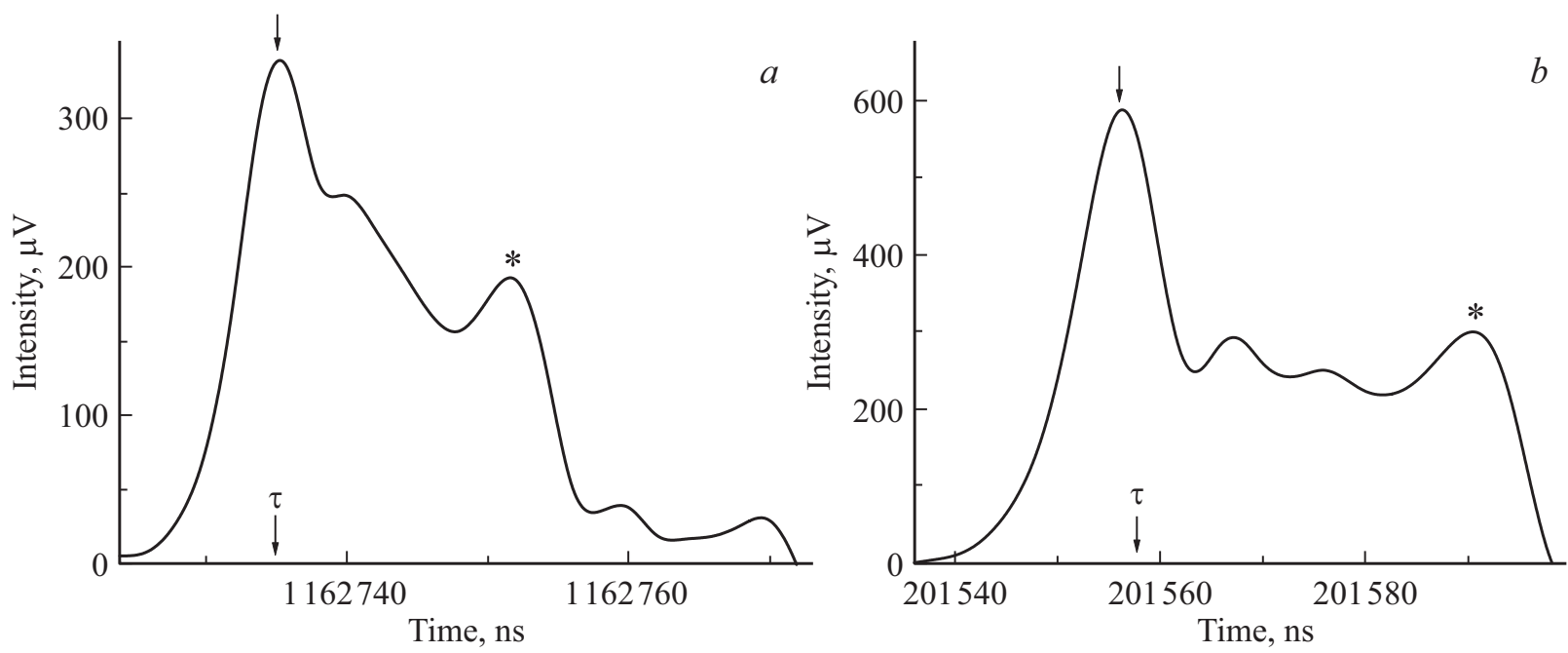

Рис. 4. Сигналы FL при ударе $(a)$ и микрорезании $(b)$ кварца. Стрелкой отмечен максимум, анализ временно́й зависимости которого позволил определить константу скорости накопления трещин $k_{i}$. Звездочками $\left({ }^{*}\right)$ отмечены третий максимум в сигналах FL, возникающих при ударе, и четвертый максимум в сигналах FL при микрорезании. Анализ этих максимумов позволил найти константу скорости затухания FL $-k_{d}$. 

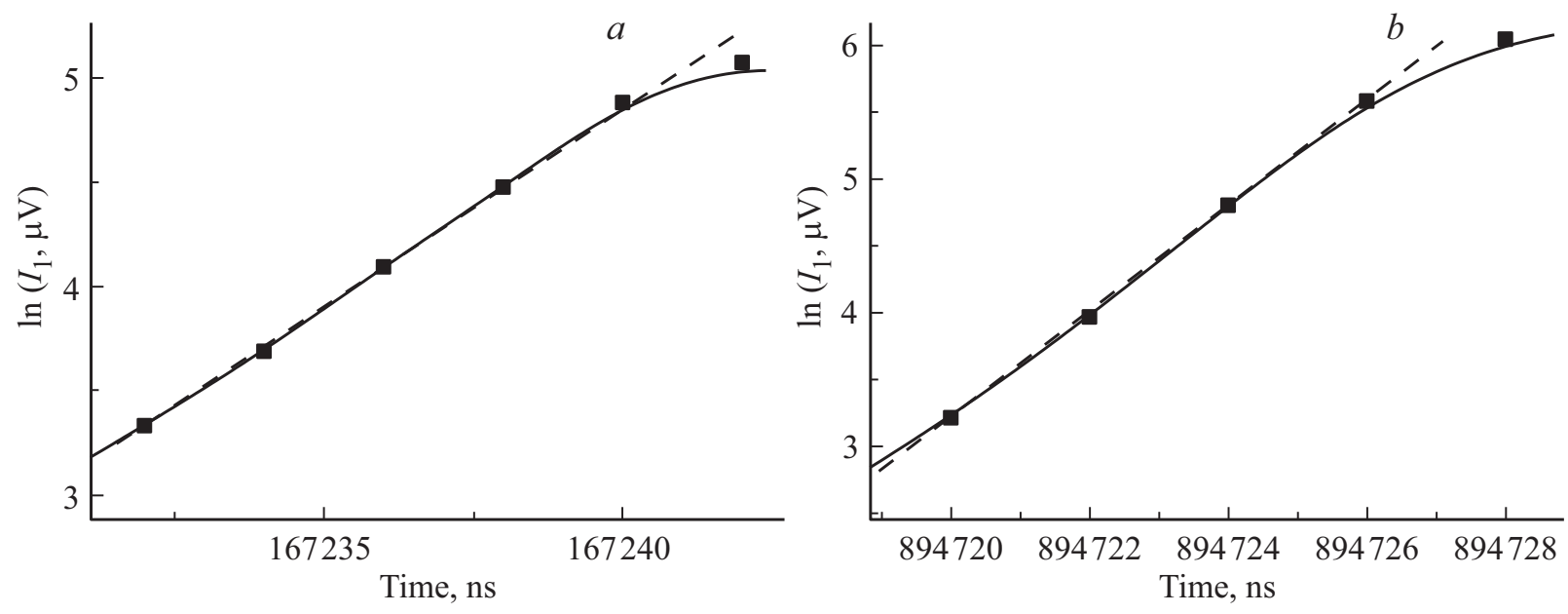

Рис. 5. Временнб́е зависимости интенсивности на начальном участке первого максимума в сигналах FL $I_{1}$ при микрорезании $(a)$ и ударе $(b)$.

небречь. Это позволяет определить константу скорости роста трещин $-k_{i}$.

Удобнее всего это сделать, анализируя временную зависимость первого максимума $I_{1}$ в сигналах FL при $t<\tau$. На рис. 5 в полулогарифмических координатах показан фрагмент начального участка временной зависимости $I_{1}$ интенсивности двух произвольно выбранных сигналов FL при микрорезании и ударе. Видно, что опытные точки укладываются на прямые линии

$$
\ln I_{1}(t)=\ln I_{1}(0)+k_{i} t,
$$

где $\ln I_{1}(0)$ - интенсивность перед появлением сигнала $\mathrm{FL}$, определяемая уровнем шумов.

Такая же линейная зависимость логарифма интенсивности начального участка первого, самого интенсивного, максимума в сигналах FL при $t<\tau$ (рис. 4) наблюдалась и для других сигналов FL, возникающих при микрорезании поверхности кварца и ударе по ней бойком.

Интенсивность FL пропорциональна числу возбужденных радикалов $\equiv \mathrm{Si}-\mathrm{O}^{\bullet}$ на поверхности зародышевых трещин, и из уравнения (1) следует, что площадь их берегов $S_{c r}$ растет экспоненциально в зависимости от времени

$$
S_{c r}=S_{0} \exp k_{i} t,
$$

где $S_{0}$ - увеличение площади трещины при прорыве барьера и слиянии двух „головных“ дислокаций, $k_{i}-$ константа скорости роста площади трещин. Оказалось, что при микрорезании $k_{i} \approx(0.20 \pm 0.04) \mathrm{ns}^{-1}$, а при ударе $k_{i} \approx(0.5 \pm 0.1) \mathrm{ns}^{-1}$.

Займемся теперь определением константы скорости затухания FL $k_{d}$ после остановки трещин. Удобнее всего оценить величину $k_{d}$, анализируя временные зависимости интенсивностей третьего максимума $I_{3}$ при ударе и четвертого максимума $I_{4}$ при микрорезании в сигналах FL (рис. 4).

На рис. 6 в полулогарифмических координатах показаны фрагменты временной зависимости интенсивности

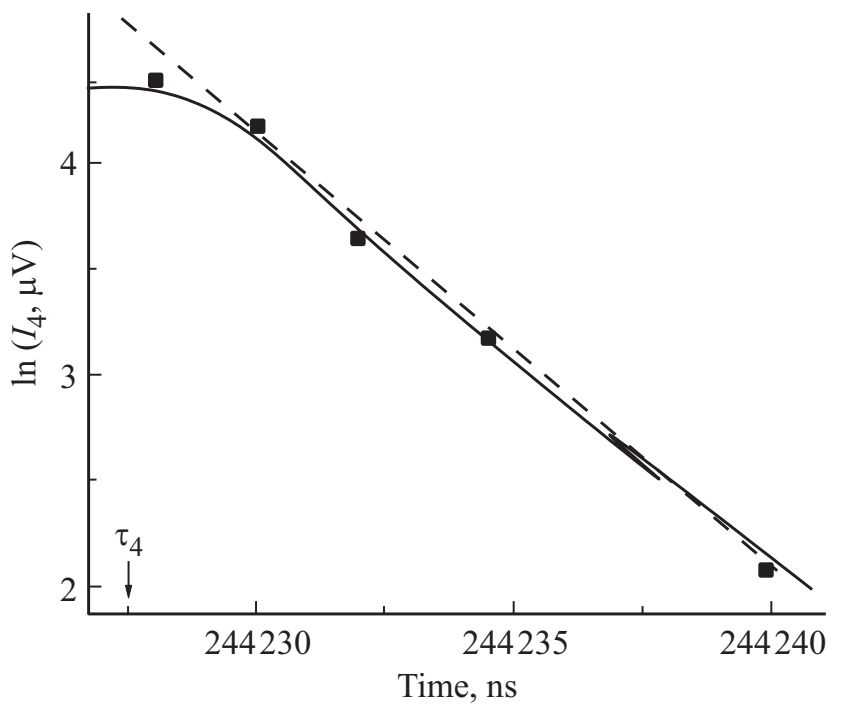

Рис. 6. Временная зависимость интенсивности четвертого максимума в сигналах FL $I_{4}$ после остановки трещины, образовавшейся при микрорезании.

четвертого максимума в произвольно выбранном сигнале FL. Видно, что экспериментальные точки укладываются на прямую линию

$$
\ln I=B-k_{d} \ln t,
$$

где $B$ - экспериментально определенный коэффициент, величина которого зависит от чувствительности фотоэлектронного умножителя; коэффициент $k_{d}$ не зависит от особенностей экспериментальной установки.

Такая же линейная зависимость логарифма интенсивностей третьего и четвертого максимумов от времени наблюдалась и для других сигналов FL при трении и ударе по поверхности кристалла кварца. Оказалось, что константа скорости затухания FL при трении и ударе одна и та же $-k_{d}=-(0.3 \pm 0.1) \mathrm{ns}^{-1}$. 


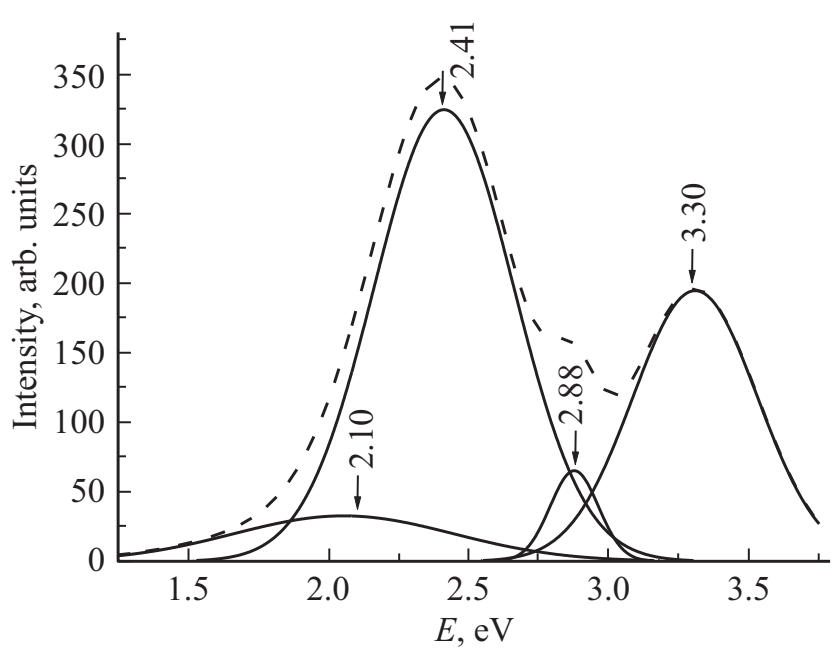

Pис. 7. Спектр PL кварца после удара по его поверхности. Штриховая линия - измеренный спектр, сплошные линии полосы, при наложении которых он образуется.

\section{4. Спектры PL кварца после разрушения}

Спектр PL поверхности образца через $20 \mathrm{~min}$ после удара приведен на рис. 7. В нем также наблюдается полоса $\sim 2.1 \mathrm{eV}$. Однако ее интенсивность значительно меньше, чем в спектрах FL. Одновременно появилось новая интенсивная полоса $-2.4 \mathrm{eV}$. Она может быть приписана радикалам $\equiv \mathrm{Si}-\mathrm{O}$ на поверхности трещин после их остановки и перестройки в течение $20 \mathrm{~min}$ после разрушения. По-видимому, релаксация напряжений после остановки трещины приводит к увеличению энергии радикалов $\equiv \mathrm{Si}-\mathrm{O}$ от 2.1 до $2.4 \mathrm{eV}$.

Выше уже отмечалось, что в спектрах FL во время разрушения, в спектрах PL после него и в спектрах $\mathrm{CL}$ наблюдается слабая полоса $3.3 \mathrm{eV}$ (рис. 2 и 7). Она соответствует центрам $\left[\mathrm{AlO}_{4} / M^{+}\right]^{0}$, где $M^{+}-\mathrm{Li}^{+}, \mathrm{Na}^{+}$, $\mathrm{H}^{+}$[12]. В спектрах FL эта полоса появляется, когда трещина пересекает центры и возбуждает их.

Природа другой слабой полосы $2.88 \mathrm{eV}$, которая наблюдалась только в спектрах PL, неизвестна.

\section{5. Размеры трещин при микрорезании и ударе по поверхности кварца}

Оценим размер зародышевых трещин. Предположим, что после прорыва барьера размер каждого из берегов зародышевой трещины возрастает на величину среднего размера кристаллографической ячейки $a \approx 0.5 \mathrm{~nm}[17,19]$. Минимальная интенсивность сигнала FL в наших опытах составила $1 \mu \mathrm{V}$. Вероятно, она соответствует слиянию двух головных дислокаций. Скорость изменения интенсивности сигнала люминесценции $d I / d t$ связана со скоростью роста площади поверхности берегов зародышевых трещин $d S / d t$ следующим об- разом: $d I / d t=Q d S / d t$, где $Q \approx a^{2}=0.25 \mathrm{~nm}^{2} / \mu \mathrm{V}$. Используя это равенство, по величине $d I / d t$ и времени роста зародышевых трещин нашли средний размер берегов зародышевой трещины $\langle S\rangle$. Оказалось, что при ударе $\langle S\rangle \approx 5 \mathrm{~nm}^{2}$, а при микрорезании - в пять раз больше, $\sim 25 \mathrm{~nm}^{2}$.

\section{6. Заключение}

При прорыве барьеров, препятствующих движению дислокаций по плоскостям скольжения, образуются самые мелкие - „первичные“ трещины, на поверхности которых расположены возбужденные радикалы $\equiv \mathrm{Si}-\mathrm{O} \bullet$. При релаксации возбуждения возникают сигналы FL, в спектре которой наблюдается полоса $2.12 \mathrm{eV}$. Длительность сигналов $\sim 50 \mathrm{~ns}$, а интервал времени между ними - несколько $\mu \mathrm{s}$. Каждый из сигналов содержит максимумы, число которых зависит от числа пересекающихся плоскостей скольжения. Определены константы скоростей роста „зародышевых“ трещин и затухания FL после их остановки. Оценены размеры площадей поверхности первичных трещин после удара $-\sim 5 \mathrm{~nm}^{2}$ и микрорезания $-\sim 25 \mathrm{~nm}^{2}$. В спектрах $\mathrm{PL}$ после разрушения наблюдали полосу $2.4 \mathrm{eV}$, которая приписана радикалам $\equiv \mathrm{Si}-\mathrm{O}$ на поверхности трещин после их образования.

\section{Конфликт интересов}

Авторы заявляют, что у них нет конфликта интересов.

\section{Список литературы}

[1] П.Г. Черемской, В.В. Слезов, В.И. Бетехтин. Поры в твердом теле. Энергоатомиздат, М. (1990). 376 с.

[2] В.И. Бетехтин, А.Г. Кадомцев. ФТТ 47, 5, 801 (2005).

[3] В.Р. Регель, А.И. Слуцкер, Э.Е. Томашевский. Кинетическая природа прочности твердых тел. Наука, М. (1974). $560 \mathrm{c}$.

[4] В.А. Петров, А.Я. Башкарев, В.И. Веттегрень. Физические основы прогнозирования долговечности конструкционных материалов. Политехника, СПб. (1993). 475 с.

[5] A.H. Cottrell. Theory of Crystal Dislocations. Gordon and Breach, N.Y. (1964). 91 p.

[6] G. Gottstein. Physical Foundations of Materials Science. Springer, Berlin (2004). 502 p.

[7] А.Н. Орлов. Введение в теорию дефектов в кристаллах. Высш. шк., М. (1983). 144 с.

[8] В.И. Владимиров. Физическая природа разрушения металлов. Металлургия, М. (1984). 280 с.

[9] A.V. Shuldiner, V.A. Zakrevskii. Radiat. Prot. Dosim. 65, 1-4, 113 (1996).

[10] В.И. Веттегрень, А.В. Пономарев, Р.И. Мамалимов, И.П. Щербаков. Физика Земли 6, 106 (2020). DOI: $10.31857 / \mathrm{S} 0002333720060125$.

[11] Л.Д. Ландау, Е.М. Лифшиц. Теоретическая физика. Наука, М. (1976). Т. 5. Ч. 1. 584 c. 
[12] M.A. Stevens Kalceff, M.R. Phillips. Phys. Rev. B 52, 5, 3122 (1995).

[13] J. Götze. Microsc. Microanal. 18, 1270 (2012). doi: $10.1017 /$ S1431927612001122.

[14] L. Trépied, J.C. Doukhan. J. Phys. Lett. Edp Sci. 43, 3, 77 (1982).

[15] N.J. Turro, V. Ramamwrite, J.C. Scaiano. Modern Molecular Photochemistry. University Sci. Press, Columbia University (2010). 1085 p.

[16] R.D. Baeta, K.G.H. Ashbee. Phil. Mag. 22, 601 (1970).

[17] М.Я. Кац, И.М. Симанович. Кварц кристаллических горных пород (минералогические особенности и плотностные свойства). Тр. Геологического института. Вып. 259. Наука, М. (1974). 228 с.

[18] C.S. Barrett, T.B. Massalski. Structure of Metals, Third Edition: Crystallographic Methods, Principles and Data (International Series on Materials Science and Technology). Pergamon, Oxford, N.Y. (1980). 654 p.

[19] L. Levien, C.T. Prewitt, D.J. Weidner. Am. Mineral. 65, 920 (1980).

Редактор Е.Ю. Флегонтова 